Carlos Henrique Menditti

\title{
Deus e o ser humano: rivalidade ou companheirismo?
}

Um estudo teológico-crítico sobre a relação entre Deus e o ser humano subjacente no romance de José Saramago,"O Evangelho Segundo Jesus Cristo", à luz da teologia de Andrés Torres Queiruga.

DISSERTAÇÃO DE MESTRADO

DEPARTAMENTO DE TEOLOGIA

Programa de Pós-Graduação em Teologia Sistemática 
Carlos Henrique Menditti

\title{
DEUS E O SER HUMANO: RIVALIDADE OU COMPANHEIRISMO?
}

\begin{abstract}
Um estudo teológico-crítico sobre a relação entre Deus e o ser humano subjacente no romance de José Saramago, "O Evangelho Segundo Jesus Cristo", à luz da teologia de Andrés Torres Queiruga.
\end{abstract}

\author{
Dissertação de Mestrado
}

\begin{abstract}
Dissertação apresentada ao Programa de Pós-Graduação em Teologia Sistemática da PUC-Rio como requisito parcial para a obtenção do grau de Mestre em Teologia Sistemática.
\end{abstract}

Orientador: Prof. Dr. Alfonso García Rubio

Rio de Janeiro, 12 de março de 2003. 
Todos os direitos reservados. É proibida a reprodução total ou parcial do trabalho sem autorização da universidade, do autor e do orientador.

\section{Carlos Henrique Menditti}

Graduou-se em Filosofia e Teologia no IFITEPS (Instituto de Filosofia e Teologia Paulo VI). É padre na Diocese de Nova Iguaçu. Leciona disciplinas na área de Teologia Sistemática na graduação em Teologia do IFITEPS e no curso de Teologia Pastoral para leigos, promovido por esse instituto.

Ficha catalográfica

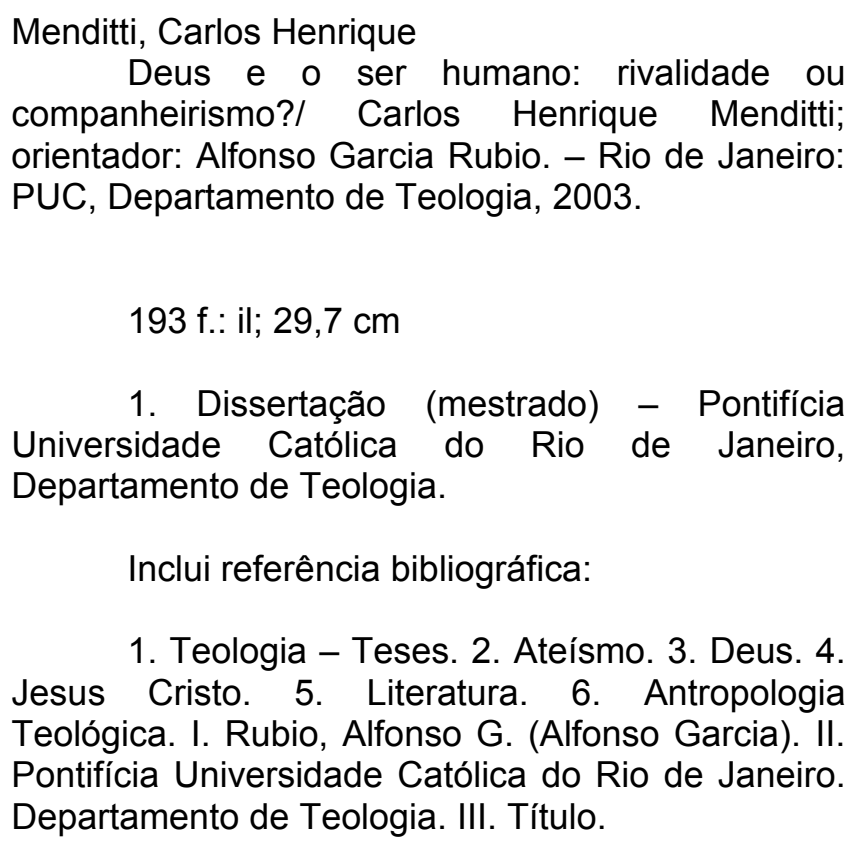

193 f.: il; 29,7 cm

1. Dissertação (mestrado) - Pontifícia Universidade Católica do Rio de Janeiro, Departamento de Teologia.

Inclui referência bibliográfica:

1. Teologia - Teses. 2. Ateísmo. 3. Deus. 4. Jesus Cristo. 5. Literatura. 6. Antropologia Teológica. I. Rubio, Alfonso G. (Alfonso Garcia). II. Pontifícia Universidade Católica do Rio de Janeiro. Departamento de Teologia. III. Título. 
Aos meus pais, Carlos Menditti Netto e Lúcia Benevenuto Menditti, que se deixando guiar por Deus, se empenharam com muito ardor na tarefa de contribuir para o meu crescimento enquanto pessoa. 


\section{Agradecimentos}

Ao prof. Dr. Alfonso García Rubio pela sugestão do tema e pela paciente e competente orientação.

Aos professores e amigos: Medoro de Oliveira Souza Neto, Paulo Roberto Hottz (in memoriam), Maria Laura Gorgulho, Antônio Alves de Melo, Marcus Barbosa Guimarães e Nilo Agostini que me incentivaram a dar continuidade aos estudos teológicos depois da graduação.

Aos meus pais e minha irmã, Carla, pela experiência afetiva que muito me animou nos momentos de cansaço da pesquisa acadêmica.

Aos colegas do grupo de estudo orientado pelo prof. Alfonso Garcia Rubio: Lindenberg F. Muniz, Leandro Frederico S. Marques, Marcos Antônio Santana, Paulo Roberto Gomes, André da Conceição R. Botelho, pela amizade e pela contribuição na elaboração desta dissertação.

Aos professores: Ana Maria Tepedino, Maria Clara L. Bingemer, Antônio Pereira da Silva, Joel Portela, Lina Boff, Mario de França Miranda, Féliz A. Pastor, pelas aulas ministradas com toda competência na pós-graduação.

À Cristiane Bittencourt, Sr. Antônio e Ir. Glória pelo auxílio na aquisição de artigos e livros.

À Helena Ormond pela disponibilidade e auxílio na impressão e na fotocopiação deste trabalho.

Ao Conselho Nacional de Desenvolvimento Científico e Tecnológico (CNPq) pelo apoio financeiro recebido ao longo do processo de pesquisa e de redação desta dissertação.

A todos amigos e amigas que com sua generosidade solidária participaram de diferentes maneiras para a realização deste nosso trabalho. 


\section{Resumo}

Menditti, Carlos Henrique. Deus e o ser humano: rivalidade ou companheirismo? Rio de Janeiro, 2003. 183p. Dissertação de Mestrado Departamento de Teologia, Pontifícia Universidade Católica do Rio de Janeiro.

José Saramago, escritor português, em "O Evangelho Segundo Jesus Cristo" apresenta a idéia de rivalidade entre Deus e o ser humano. Jesus, concebido como humano até na pecabilidade, é descaracterizado em sua humanidade como pessoa, devido à supressão de sua liberdade e à desvalorização de sua vida por Deus. O humano Jesus é conduzido por Deus forçosamente à morte na cruz. Como "filho de Deus", Jesus é obrigado a assumir uma missão contra a sua vontade: fazer-se reconhecer em sua filiação divina e morrer crucificado como tal para que Deus possa se tornar um deus universal (católico). Deus é apresentado como um poder tirânico preocupado somente com seus interesses. A relação entre Deus e Jesus é conflituosa. É uma relação de interesses opostos; uma relação entre senhor e escravo.

Andrés Torres Queiruga, ao contrário do autor português, preocupa-se, em sua reflexão teológica, em romper o mal-entendido que, desde o início da modernidade, levou Deus a ser percebido como rival do ser humano. Para ele, Deus é afirmação da pessoa humana, pois seu interesse maior é a realização do humano. As idéias de "criação por amor" e de "Deus como antimal" procuram confirmar essa intuição.

A teologia de Andrés Torres Queiruga nos possibilita responder a acusação fundamental de José Saramago a respeito da desumanização que Deus engendra no ser humano. A relação entre Deus e Jesus inventada por José Saramago carece de sentido diante do fundamento da teologia de Torres Queiruga e de toda a fé cristã, a saber, a relação entre Jesus e Deus da revelação bíblico-cristã. O Jesus bíblico, ao contrário do Jesus fictício, faz uma experiência humanizante de Deus, pois percebe que Deus é $A b b a ́$ de amor infinito. A verdade apontada por Torres Queiruga é a de que Deus se preocupa fundamentalmente não consigo mesmo, mas com a pessoa humana e com sua realização. Deus é o nosso "grande companheiro".

Palavras-chave: ateísmo; Deus; Jesus Cristo; literatura; antropologia teológica. 


\section{Résumé}

Menditti, Carlos Henrique. Dieu et l'être humain: rivalité ou solidarité? Rio de Janeiro, 2003. 183p. Dissertation de Maïtré - Départament de Théologie, Pontifícia Universidade Católica do Rio de Janeiro.

Dans "O Evangelho Segundo Jesus Cristo", José Saramago, écrivain potuguais, donne l'idée d'une rivalité entre Dieu et l'être humain. Jésus y est présenté comme humain jusque dans la propension au péché. En tant que personne, il en vient à perdre les caractéristiques de son humanité dans la mesure ou il se voit privé de son livre arbitre et où sa vie perd toute valeur aux yeux de Dieu. L' homme Jésus est obligatoirement conduit par Dieu à mourir sur la croix. Comme "fils de Dieu", Jésus est obligé d' assumer une mission contre sa volonté: faire reconnaître sa filiation divine et mourir crucificié comme tel pour que Dieu puisse devenir un dieu universel (catholique). Dieu est représenté dote d'un pouvoir tyrannique préoccupé seulement de ses seuls interêts. La relation entre Dieu et Jésus est conflictive. Il s'agit d'une relation d'interêts opposés, une relation entre seigneur et esclave.

Andrés Torres Queiruga, dans sa réflexion théologique, cherche à démonter le mal-entendu, qui depuis les débuts de la modernité, conduit a percevoir Dieu comme rival de l'être humain. Pour lui, Dieu est l'affirmation de la personne humaine, car son plus grand interêt c'est justement la réalisation de l'humain. Les idées de "création pour amour" et de "Dieu comme Anti-mal" cherchent à confirmer cette intuition.

La théologie de A. Torres Queiruga nous donne la possibilité de répondre à l'accusation fondamentale de José Saramago au sujet de la déshumanisation que Dieu cause à l'être humain. La relation entre Dieu et Jésus inventée par José Saramago perd son sens devant les fondements de la théologie de A.Torres Queiruga et de toute la foi chrétienne, à savoir, la relation entre Jésus et Dieu de la révélation biblique chrétienne. Le Jésus biblique, au contraire du Jésus fictif, fait l'expérience humanisante de Dieu, car il perçoit que Dieu est Père “Abbá”, amour infini. La vérité observée par A.Torres Queiruga est d'un Dieu qui se préoccupe fondamentalement, non pas de lui-même, mais de la personne humaine et de sa réalisation. Dieu est notre "grand compagnon".

Mots-clefs: atheísme; Dieu; Jésus-Christ; anthopologie théologique; litterature 


\section{Sumário}

$\begin{array}{ll}\text { Introdução geral } & 01\end{array}$

1. O Deus desumano e o ser humano desumanizado de José Saramago

Introdução

1.1. "O Evangelho Segundo Jesus Cristo" 08

1.1.1. O autor

1.1.2. O romance

1.1.3. Reações e críticas

1.2. A identidade do Jesus de José Saramago

1.2.1. A humanidade

1.2.1.1. Humano como os outros

1.2.1.2. O sentimento de culpa

1.2.2. A "divindade" e a filiação divina

1.2.2.1. A concepção divina

1.2.2.2. A missão

1.2.2.3. A morte como filho de Deus

1.3. A imagem do Deus de Saramago

1.3.1. Deus segundo os personagens do romance

1.3.1.1. Deus segundo José

1.3.1.2. Deus segundo Maria de Nazaré

1.3.1.3. Deus segundo Jesus

1.3.1.4. Deus segundo Maria de Magdala

1.3.1.5. Deus segundo o Diabo

1.3.1.6. Deus segundo outros personagens

1.3.2. Deus segundo os comentários do autor

1.3.3. O personagem Deus

1.3.3.1. O personagem Deus no primeiro encontro com Jesus

1.3.3.2. O personagem Deus no segundo encontro com Jesus

1.3.3.3. O personagem Deus na morte de Jesus

1.4. A relação entre Deus e Jesus

1.4.1. A supressão da liberdade
07

07

22

23

24

28

30

31

32

35

37

37

37

39

40

42

43

45

46

49

49

50

53

54

54 
1.4.1.2. Filiação divina, sinônimo de escravidão 57

1.4.1.3. Missão imposta 58

1.4.2. A negação da vida 62

1.4.2.1. Aliança de sangue 62

1.4.2.2. "Filho de Deus", "cordeiro de Deus" 63

1.4.2.3. Missão, morte de cruz 65

Conclusão 66

2. Deus como afirmação do humano em Andrés Torres Queiruga 69 Introdução 69

2.1. Um Deus próximo e não intervencionista 70

2.1.1. A imagem deturpada de Deus como rival do ser humano $\quad 70$

2.1.2. A verdadeira imagem de Deus: o Abbá de Jesus 78

2.1.3. A presença amorosa de Deus na criação 84

2.1.4. A revelação de Deus na realização humana 93

2.2. Deus e o problema do mal 97

2.2.1. O dilema de Epicuro 99

2.2.2. A inevitabilidade do mal no mundo 105

2.2.3. Deus ao nosso lado contra o mal 108

2.2.3.1. O mundo tem sentido apesar do mal? 108

2.2.3.2. Deus como antimal 111

2.2.3.2.1. Deus contra o mal no Antigo Testamento 111

2.2.3.2.2. Em Jesus, Deus ao nosso lado contra o mal 113

2.2.3.2.3. Em Jesus, Deus implicado na realidade do mal 115

2.2.3.2.4. Em Jesus, Deus vence o mal 116

2.2.3.3. A salvação a partir da história 120

2.2.3.4. O núcleo de uma nova coerência 123

2.3. A religião como experiência humanizadora 127

2.3.1. Religião como realidade humana 127

2.3.2. A religião não é um peso à existência 129

Conclusão 134 
3. Crítica à relação entre Deus e o ser humano postulada por José Saramago

3.1. A "teologia atéia" de José Saramago

137

3.2. O Deus desumano de Saramago diante do Deus de Jesus 142

3.2.1. A construção de um "fantasma" que se opõe à vida humana

3.2.1.1. O determinismo divino

3.2.1.2. Um deus intervencionista

3.2.1.3. A onipotência divina

144

3.2.1.4. A paternidade divina mal-compreendida

3.2.2. O Deus de Jesus 150

3.3. O ser humano desumanizado pelo Deus de Saramago 154

3.3.1. Jesus ficcional, o protótipo do humano despersonalizado 154

3.3.2. O ser humano a serviço de Deus? 159

3.3.3. Deus deseja a morte do ser humano? 163

$\begin{array}{ll}\text { Conclusão } & 167\end{array}$

$\begin{array}{ll}\text { Conclusão geral } & 170\end{array}$

$\begin{array}{ll}\text { Referência bibliográfica } & 173\end{array}$ 